\title{
Enriching the Italian Genuine Saving with water and soil depletion: national trends and regional differences
}

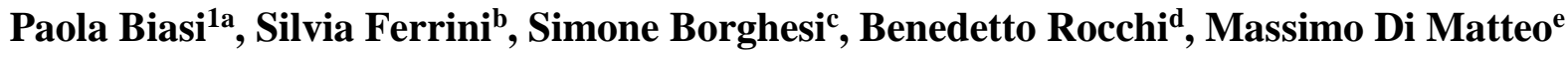 \\ apaola.biasi83@gmail.com, University of Siena, Department of Political Science and International \\ bs.ferrini@uea.ac.uk, CSERGE-University of East Anglia and University of Siena, Department of Political Science and \\ International \\ csimone.borghesi@unisi.it, University of Siena, Department of Political Science and International \\ dbenedetto.rocchi@unifi.it, University of Florence, Department of Economic Science and business \\ emassimo.dimatteo@unisi.it, University of Siena, Department of Political Science and International
}

\begin{abstract}
National and international governments aim to promote the responsible management of the natural capital but measuring its contribution to economic growth is still a challenging exercise. The natural capital supports a plurality of environmental functions whereas the economic growth is frequently measured by aggregated indicators. In this paper, we propose an extended version of the Genuine Saving macro indicator to account for water and soil depletion. Further, as natural capital is spatially heterogeneous we estimate Genuine Saving for Italy for the period 2000-2015 at the regional level. Whilst the case study produces specific results for Italy the methodological framework is broadly applicable to other states. The Italian comparison shows that soil and water provide an absolute change of roughly $1 \%$ of the GS but average relative regional variations are between 5 and 33\% of GDP, showing that the geographical scale of sustainability analysis is a crucial element for responsible management of national assets. The methodological contribution suggests that the Genuine Saving can support policy makers in developing targeted policies for sustainable growth.
\end{abstract}

Keywords: Adjusted net savings, Beyond GDP, Loss of soil, Regional sustainability.

JEL code: E01, Q56, R11.

\section{Introduction}

The need of measuring the performance of nations has been historically fulfilled by GDP as an indicator of economic activities. Nowadays, the focus on the multiple dimensions of nations' performance requires a shift from GDP towards more comprehensive indicators (Ciommi et al 2017). GDP has been unable to properly take into account the environmental and social impact of economic growth; these aspects have a central role in societal progress, and constitute a central issue in the concept of sustainability (Stiglitz et al. 2010).

\footnotetext{
${ }^{1}$ The first author acknowledges funding from the University of Siena for a Postdoc fellow at the Department of Political Science and International.
} 
After the publication of the Bruntland commission report (WEDC, 1987), the idea of sustainability, as well as the problems related to its measurement have been at the center of the public debate. A rich academic literature discusses the normative and methodological problems posed by this challenge; more specifically, the concrete measurement of sustainability is still an open question and several scholars contributed to the elaboration of different approaches (i.e. weak versus strong sustainability). Since the concept itself is complex and multidimensional, it is hard to capture all its relevant aspects in a single indicator or even a set of indicators. Due to this, a plethora of different tools are now available (Atkinson et al., 2014).

The economic literature has been dominated by the idea that the ability to satisfy the needs of present/future generations (WCED, 1987) crucially depends on the preservation (or even the increase) of the economic, natural, social and human capital. This rather basic consideration has been very fruitful, leading to the advancement of an influential strand of literature, whose main focus is on the components that "produce" human well-being (Polasky et al. 2015). In that perspective, a proper assessment of sustainability starts from the definition of the elements that constitute the "productive base" of human well-being and wealth. The eventual erosion of these endowments undermines the ability to support intra- and inter-generational development. Accordingly, the measurement of sustainability requires to monitor and evaluate changes in capital assets to test the ability to sustain well-being. A non-declining wealth has to be preserved over time; this is a necessary condition for sustainable development (Dasgupta et al., 2001).

The Genuine Savings (GS) is a sustainability indicator also called Adjusted Net Savings or Adjusted Investments (Pearce and Atkinson, 1993; Hamilton and Clemens 1999; Hamilton and Atkinson 2006) that links social welfare theory, capital stock management and well-being. It measures "true" savings, that is, the changes in total wealth, accounting for the variation in produced capital, natural capital and human capital that occurs in a period of time (e.g. a year); a persistently negative value of the index signals an unsustainable development path and an insufficient rate of produced capital accumulation. The main advantage of this indicator is that it is directly comparable with GDP being expressed in monetary terms. A major disadvantage is the need to monetize social and environmental assets. Stiglitz et al. (2010) observe that a desirable feature of sustainability indicators is their ability to signal unsustainable pathways in current trends. We claim that Genuine Saving fulfills this role but still needs a greener vision to better account for environmental damages.

The effort in measuring sustainability trends is confirmed by the production of different national or macroregional levels indicators (such as the Inclusive Wealth initiative (UNEP 2012, 2014); Better Life Index for 362 Regions (OECD 2014), World Bank GS for more than 100 countries (World 
Bank, 2006, 2011)). The World Bank GS only accounts for depletion of natural capital due to subsoil resources, forests exploitation, $\mathrm{PM}$ and $\mathrm{CO} 2$ emission. While these resources are important it is easy to sustain that also water and soil are critical assets for sustainable development. According to the World Bank estimates, EU Members States and many other developed countries present a positive GS results, however relevant natural and social assets are neglected (Schepelmann et al., 2010).

The definition of World Banks GS has been extended and tailored for specific countries reflecting the richness of data on air pollutants or other assets (e.g.: Ferreira and Moro, 2011, 2013 for Ireland, Mota and Martins, 2010 for Portugal and Hanley, 2015 for a review). Brown et al. (2005) and Hanley et al. (1999) propose measurements of subnational GS (respectively for Queensland and Australia, and Scotland), showing that important divergences in national and regional sustainability paths might be masked by the World Bank indicator. Clark and Lawn (2008) revise benefits and challenges of sub-national indicator and Biasi and Rocchi (2016) present a first attempt to derive sub-national GS estimates for Italy. At the best of our knowledge, none of these previous studies include water and soil depletion as components of the natural capital in the GS.

The main aim of this paper is twofold: determining the Genuine Savings for the Italian regions and extending the World Bank empirical specification to include soil and water management. Data availability is the criteria followed to incorporate these natural assets in the national and regional GS indicator. The paper contributes methodologically to enhance the specification of sustainability indicators and empirically presents the sustainability trends of Italian nation and regions over a fifteen years-time period. This spatial and temporal specification of the GS offers a promising policy instruments to improve environmental management at both at the local and the national level. Complementary to Ciommi et al (2017), our GS regional analysis shows how unstainable pathways can occur at sub-national level and a variety of factors that can play a role.

The paper is structured as follows: Section 2 describes the theoretical model of the GS and the empirical specification used by the WB in its calculation; Section 3 describes the data used for physical and monetary accounting in our estimates. Section 4 presents and discusses the results. Section 5 concludes.

\section{The Genuine Savings}

The GS was initially proposed by Hamilton and Clemens (1999) but the intellectual roots dated back to Weitzman (1976) (see Pearce 2002; Fleurbaey, 2009). Weitzman (1976) shows that the current Net National Product (NNP), under certain conditions, can be considered a measure of the 
present value of future consumption where the capital also includes natural resources. Solow (1974) raises awareness on the role of limited natural resources for growth and intergenerational equity; based on the assumption of perfect substitution between capital-labour and natural resources, he states that current generation can "consume" exhaustible resources as long as it adds to the stock of reproducible capital. Building on this and relying on the Hartwick rule (1977), Solow (1986) shows that reinvesting natural resource rents can help maintaining capital stock constant over time, providing a rule of thumb for policy makers to preserve consumption possibilities in intergenerational terms. The principle of "weak sustainability" shapes the Genuine Savings indicator and initially Pearce and Atkinson (1993), Hamilton and Clemens (1999) and Atkinson and Hamilton, (2007) discuss the implications of using sustainability measurements.

From a theoretical point of view, the Genuine Savings indicator is based on the Hicksian definition of income as the maximum amount that can be consumed in one period without compromising the ability to afford the same level of consumption in the following period (Hicks, 1946). The indicator is built on the framework of the green national accounting, together with a rearrangement of the Hartwick rule (Hartwick, 1990) and it requires that the depletion of exhaustible natural resources should be offset with investments in other forms of capital to preserve the total stock of wealth and well-being over the long run.

Four types of adjustments are necessary to transform the standard savings, as measured in national accounting, into "genuine savings". Figure 1 represents the main steps to calculate the National savings (that is gross national income less private and public consumption) plus the public investment in education (private investments in education are excluded), minus the consumption of fixed capital, the natural resource extraction (natural capital includes oil and natural gas, mineral and forest depletion) and environmental degradation (air pollutants) all valued in monetary terms. 


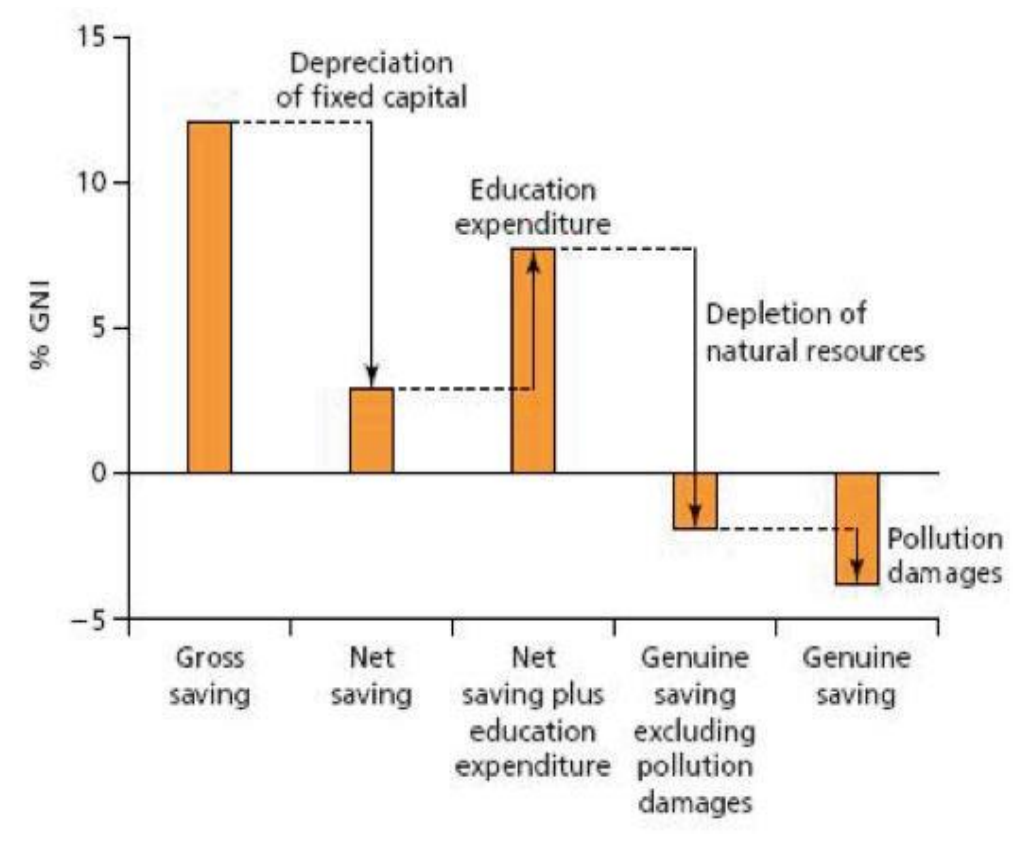

Figure 1. Definition of Genuine Saving [Source: The World Bank (2006)].

All components are expressed as percentage of Gross National Income (GNI). Given the weak sustainability assumption, different forms of capital (productive, natural and human) are perfect substitutes and the Genuine Savings (GS) suggests that an economy is sustainable if its net savings are non-negative. The negative value of the GS signals that current well-being is based on an unsustainable mismanagement of resources (due to overconsumption or underinvestment). A negative GS will lead to the erosion of total wealth implying future lower levels of wellbeing (Pearce and Atkinson, 1993). Being able to provide suggestions on future implication of current choices, the GS is a forward looking indicator that can be used for policy decision making (Stiglitz et al., 2010, UNECE 2009).

Despite its popularity and promising features the GS presents drawbacks. First, the World Bank GS (Bolt et al., 2002), includes only a small subset of natural components such as depletion of minerals, metals, forests and environmental pollution (carbon dioxide and particulate matter emission). However, other crucial resources such as water, soil and, in general, biodiversity are missing. The World Banks needs to provide meaningful cross-country comparisons and, as a consequence, it must focus on homogeneous and comparable data, rather than broader measurement of natural capital assets.

Second, as a national aggregated indicator, the GS can hide unsustainable development pathways at regional or local level. This can be a serious issue when the aim is to monitor relative 
overconsumption/underinvestment. The natural capital includes spatially heterogeneous resources (Fisher et al 2009): the sustainability of the aggregate is not necessarily based on the sustainable progress of its parts, so that the choice of the geographical scale for measurement is not neutral for the final results. Hanley et al. (1999) disentangle the GS for the United Kingdom and show that overall positive GS masks a negative performance for Scotland. Moreover, even though the sustainability challenge is a global issue, "political actions and the potential to change development paths is predominantly a regional, national or even local privilege. For this reason it remains imperative to measure whether sub-global entities - particularly nations, but also sub-national jurisdictions [...] - are developing sustainably" (UNECE 2009). Then, monitoring long-terms trends in sustainability with measurement tailored at the subnational level may provide useful information to support policy decision making.

The paper extends the Hanley et al. (1999)'s approach presenting the GS estimates for NUTS2 regions in Italy over time including water and soil depletion. In our opinion, however, the approach presented in the paper is applicable across countries that provide regional gross savings..

\section{Data and methods: the traditional components of the Genuine Savings}

According to Atkinsons et al. (2014) the standard GS in a given year of an economy can be defined as follows:

\section{Standard GS = Gross Savings - Depreciation of fixed Capital + Public investments in Education \\ - Depletion of Enegy Resources - Depletion of Minerals \\ Eq 1 \\ - Net Depletion of Forests - CO2 Damages - PM Damages}

Following the World Bank (Bolt et al. 2002) empirical implementation as in eq. 1 Biasi and Rocchi (2016) suggest to measure the GS for Italian regions. In this paper we also propose to include soil and water degradation as per eq. 2 and to compare national and regional trends.

\section{Extended GS = Gross Savings - Depreciation of fixed Capital \\ + Public and Private investments in Education \\ - Depletion of Enegy Resources - Depletion of Minerals \\ - Net Depletion of Forests - CO2 Damages - PM Damages \\ - Damages of soil sealing - Damages of water losses and degradation}

Furthermore, the prices for subsoil depletion (energy and minerals) and pollution damages (PM10) are calculated considering alternative source of data, mimicking the challenges in calculating the GS when multiple source of information are available. The price of minerals is based on two 
different estimates of unit rents and extraction costs and the PM10 costs account both for high and low Value Of a statistical Life Year (VOLY). The objective is to use all the estimates available at national and regional levels for all considered assets in 2000, 2005, 2010 and 2015. This allows to provide GS estimates at the regional level under an optimistic and pessimistic scenario.

The National Office of Statistics provides the National Accounts figures (ISTAT, 2017) to determine the Net National Savings and disaggregate them at the regional level ${ }^{2}$. Regional public and private expenditures in education are included ${ }^{3}$, as a proxy for investments in human capital.

Subsoil depletion is accounted for as oil and natural gas extraction rent. The physical quantity of natural capital extracted is monetized using international market prices minus extraction costs. Data on quantity extracted are provided by the Italian Ministry of Economic Development; the value of the unit rent for natural gas and oil is estimated by the World Bank for Italy. As the paper aims to test the impact of data availability on GS measure, we present an alternative approach which employs international market price for oil (British Petroleum, 2016) and cost of oil production (development costs) as elaborated by Nomisma Energia (2012). These alternative sources of data present higher cost of oil extraction and consequently, a lower unit rent for oil with respect to WB estimates. Both values will be presented in the empirical application.

CO2 and PM10 emissions are the air pollutants included in the standard measures of GS. Ispra (2019) provides regional CO2 emissions for the period considered. CO2 is valued at 37 \$ per ton as estimated by OIRA (2017) and we account for the incremental damages of CO2 emission over the time span. Regional PM10 emissions are derived by the National Inventory of Pollutants (ISPRA, 2019) while estimates of economic damages are based both on low and high Value Of Life Years (VOLY) as provided by EEA (2014).

\subsection{Complementing the GS with Soil data}

Complementing the GS with soil and water degradation is one objective of the paper but data availability is a constraint and our approach is to rely on available information. Soil sealing represents the main source of biodiversity loss and also causes soil degradation. The physical data on soil sealing are provided by ISPRA - Soil monitoring network. The network accounts for artificial land cover in the period 1956 to 2015 and previous studies report the impact of soil sealing

\footnotetext{
2 The ratio of regional investments over national investments are used to disaggregate the national figure, according to the methodology described by (Biasi and Rocchi 2016).

${ }^{3}$ Following the World Bank approach, we consider expenditures in education as a proxy of human capital formation. As detailed in eq. 1 and 2 the WB framework includes only public expenditures whereas our extended indicator captures private and public investments in education.
} 
in Italian regions (Munafo et al 2013). Based on this data, we compute the regional average soil consumption in hectares over time as the percentage of regional area of "arable land" transformed into artificial surfaces in a given period ${ }^{4}$.

As the soil sealing produces a loss of agriculture values already included in the gross saving and data on costs of soil erosion are not available, the monetary estimates of damages due to soil sealing are obtained considering the loss of $\mathrm{CO} 2$ sequestration potential (as a proxy of regulating services). As detailed information on the nature of soils sealed are not available the lost carbon sequestration potential is assumed to be the same for each hectare of soil. Following Sallustio et al. (2015), this value is set to $58.1 \mathrm{Mg} \mathrm{C} / \mathrm{ha}$ for a conservative estimate. The same cost of carbon provided by OIRA (2017) is used to monetize the sealing of soil ${ }^{5}$. The mean economic loss of soil is approximately 4800 euro/ha over the period considered.

\subsection{Complementing the GS with Water data}

Given the availability of regional data two dimensions of water depletion are included in the analysis: 1) water quality degradation due to urban and industrial pollution; 2) quantity of potable water lost (that is, water abstracted and then wasted due to inefficient distribution systems) ${ }^{6}$. The National Office of Statistic (ISTAT 2006, 2009, 2015) provides physical data for both dimensions.

Urban and industrial pressures are responsible for water quality degradation and per-capita unit of organic loading is the quantity of attention in this paper. In physical terms, wastewater is an input to the water system, since it contributes to water return flows from the economy to the environment (directly or indirectly through treatment), and may be available for other uses within the economy; nonetheless, degradation has an impact in terms of sustainability, since these flows are characterized by lower quality with respect to abstracted water (UN, 2012). The monetization of the

4 Despite this assumption might appear too simplistic, it is supported by the evidence that the expansion of urban area and the increase in soil sealed from 1990 to 2008 in Italy occurred at the expense of arable land (mainly cropland -approximately the 75\%-, and orchards- less than 12\%). Other natural areas (e.g., forests) are marginally involved in this process (Marchetti et al., 2012).

5 Each tonn of carbon is equal to 3,67 ton of carbon dioxide.

${ }^{6}$ Physical data on water losses in 2000 refers to data provided by ISTAT (2006) for the year 1999; quantity in 2010 refers to data provided for 2008 by ISTAT (2009). For water pollution, data on 2000 are calculated through linear interpolation based on available data (ISTAT, 2009); also in this case data for 2010 refers to value provided by ISTAT for the year 2008. We assume that drinking water losses due to inefficiency in the water distribution system require many years to return into the system. 
per-capita unit is estimated as 14.56 Euro per unit of organic load (equivalent inhabitant) as derived by Pulselli et al. (2006) ${ }^{7}$.

As water losses due to inefficient water supply network can have different interpretations our choice is supported by the following considerations. According to UN's System for EnvironmentalEconomic accounting for Water (UN, 2012), leaks from pipe have to be considered as "return flows" from the economy to the environment. Leakages from water supply networks may contribute to recharge aquifers; at least part of these losses can turn out to be a resource for the water system and become available for abstraction in the future (UN, 2012). On the other hand, it must be observed that wasted potable water requires long natural hydrologic process (or expensive artificial treatment) before the availability for use of the resource is restored to its initial level both in terms of quantity and quality.

Leaks of potable water may support the refill of aquifers; but water after leakages is not equivalent, in terms of quality, to drinking water. This problem has crucial implications, as drinking water supports human beings and quality of life. In Italy, groundwater is the main source of potable water and contributes to approximately $84 \%$ of total water abstraction as it requires less treatment due to higher quality with respect to surface water (ISTAT, 1999). Persistent potable water leakage problems prompt an increase abstraction from aquifers and depletion of subsoil water which can alternatively support ecosystems and biodiversity. Further, "unnecessary abstraction may have negative hydromorphological consequences and may cause higher concentrations of pollution in the originating water body from which the water is abstracted" (EU, 2015). Finally, drinking water leakages generate inefficiency that cannot be neglected in a macroeconomic perspective of sustainability (i.e. waste in terms of electricity for abstraction, additional environmental pressure for treatment, use of chemicals etc.). Including wasted potable water in the GS indicator provides (at least partially) a measure of pressures and damages on water resources due to unrealized measures (investments) to avoid leakages (EU, 2015).

Data on water supplied and received, and percentage of dispersion at the regional level are provided by the National Office of Statistics and the monetization of these losses is obtained multiplying the quantity dispersed by the average regional Federconsumatori estimates of typical domestic water consumption fees $(1999,2005,2008,2015)^{8}$.

\footnotetext{
${ }^{7}$ The authors consider the cost of treatment of wastewater in a standard purification plant.

${ }^{8}$ Federconsumatori collects data on domestic tariffs in major Italian cities; based on this information we compute the average tariff at the regional level; alternatively, we impute the national average if local data are not available. We are aware that this is a rough approximation of the value of water lost; however, the
} 


\section{Results}

Results firstly describe at the national level the benefits of enhancing the GS with soil and water data and subsequently regional GS analysis is presented. Estimates with and without different natural assets are reported to appreciate the contribution of the missing components. The national GS is calculated following two approaches: theWB approach and a revised national estimates at low (Min) and high (Max) values for oil and gas rents and PM10 damages. Figure 2 contrasts our estimates for the standard World Bank GS calculation for the period 2000-2015.

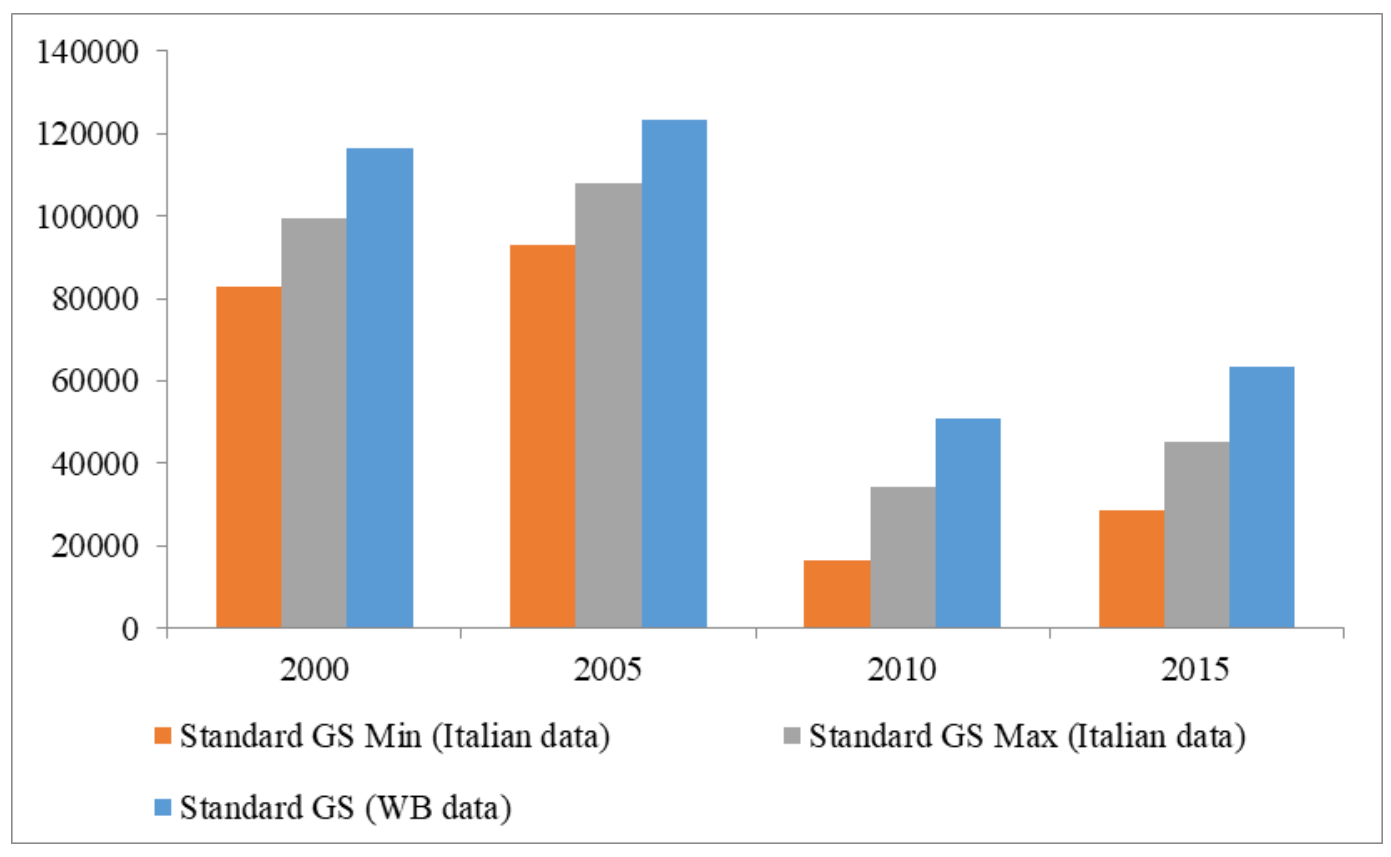

Figure 2. Genuine Saving using WB and national data for Italy (values in millions of euro Euro)

Results are comparable although our estimates appear slightly more conservative than the WB. Over time, Italy presents a positive (but decreasing) GS, with a modest recovery in 2015 . The wealth trend is unequivocally the same, results show a steady reduction of the value of the index over the period considered; it is worth noticing that as previously mentioned, it is well known that the sustainability performance of developed economies may be overvalued in WB estimates of the index, mainly due to problems in data quality.

Figure 3 shows the impact of considering also soil and water components in the estimate of GS as the value of the index shows a further decrease. Considering the optimistic scenario (max GS), at the country level, the inclusion of soil and water depletion generates a reduction of approximately

aforementioned survey is the only systematic assessment of the "price" of this potable water all over the country. 
4\% with respect to the "standard" calculation of GS in 2000 and 2005, 15.12\% in 2010 and $16.97 \%$ in $2015^{9}$. These findings support the idea that expanding the empirical framework of the index has a non-trivial impact on final results, leading the GS indicator to better reflect the sustainability performance of countries.

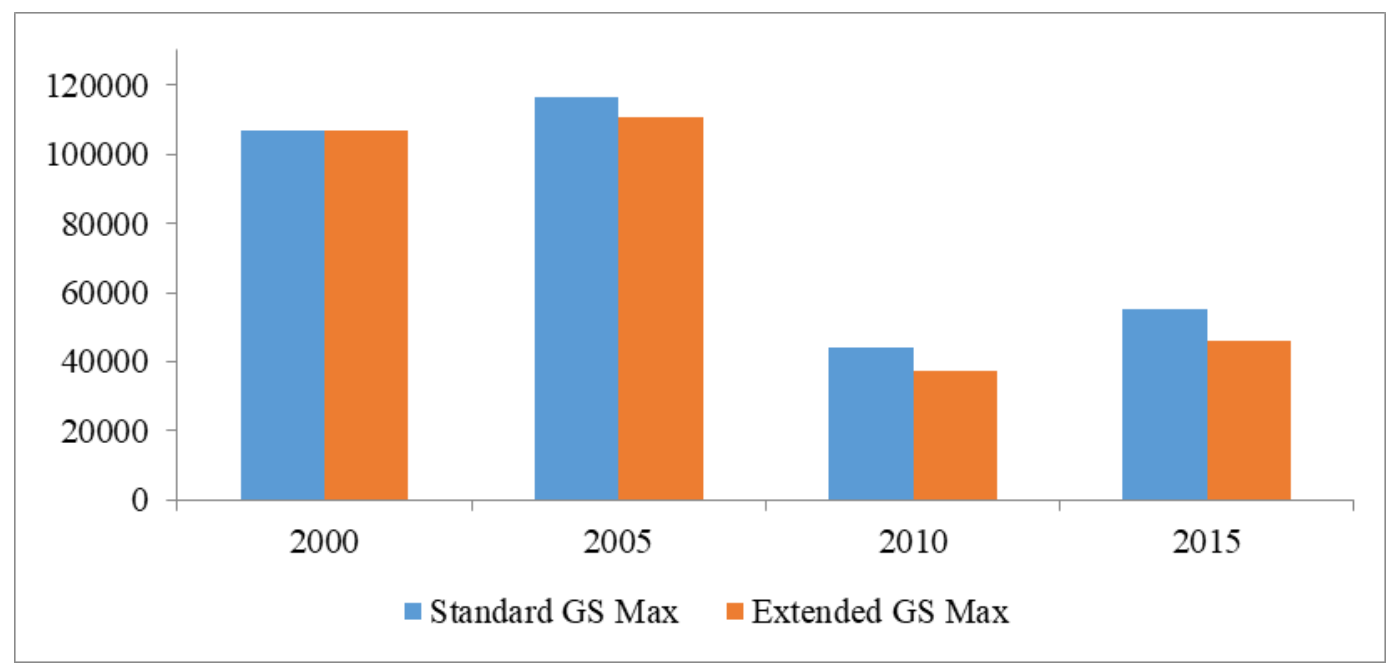

Figure 3 Extended Genuine Saving with soil and water components for Italy (values in Euro)

Figure 2 and 3 show a clear decline in GS from 2000 to 2010 and a modest improvement in 2015; however, the regional analysis can contribute to understand the dynamic of changes. The spatial disaggregation of the standard and extended GS (with or without water and soil components) we claim is an important step in enhancing the information provided by the indicator.

Figure 4 reports the regional values of standard GS in millions of euro in 2015 and shows that in absolute terms Campania, Lombardia, Lazio and Sicilia show the highest performance, while other regions, as for example Friuli-Venezia Giulia, Abruzzo, Molise and Calabria are very close to zero. A better comparison which captures economic and geographical differences is the amount of savings measured as a percentage of regional GPD as reported in Tab1.

9 For the "pessimistic scenario" estimation (min GS), the reductions with respect to the WB estimates of the GS become $6 \%$ in 2000 and 2005 and 40\%, 32.9\% in 2010 and 2015. The considerable impact registered in 2010 is the result of a combined effect: the increase of soil and water depletion and, mostly, the considerable reduction in standard net savings due to the macroeconomic downturn. 


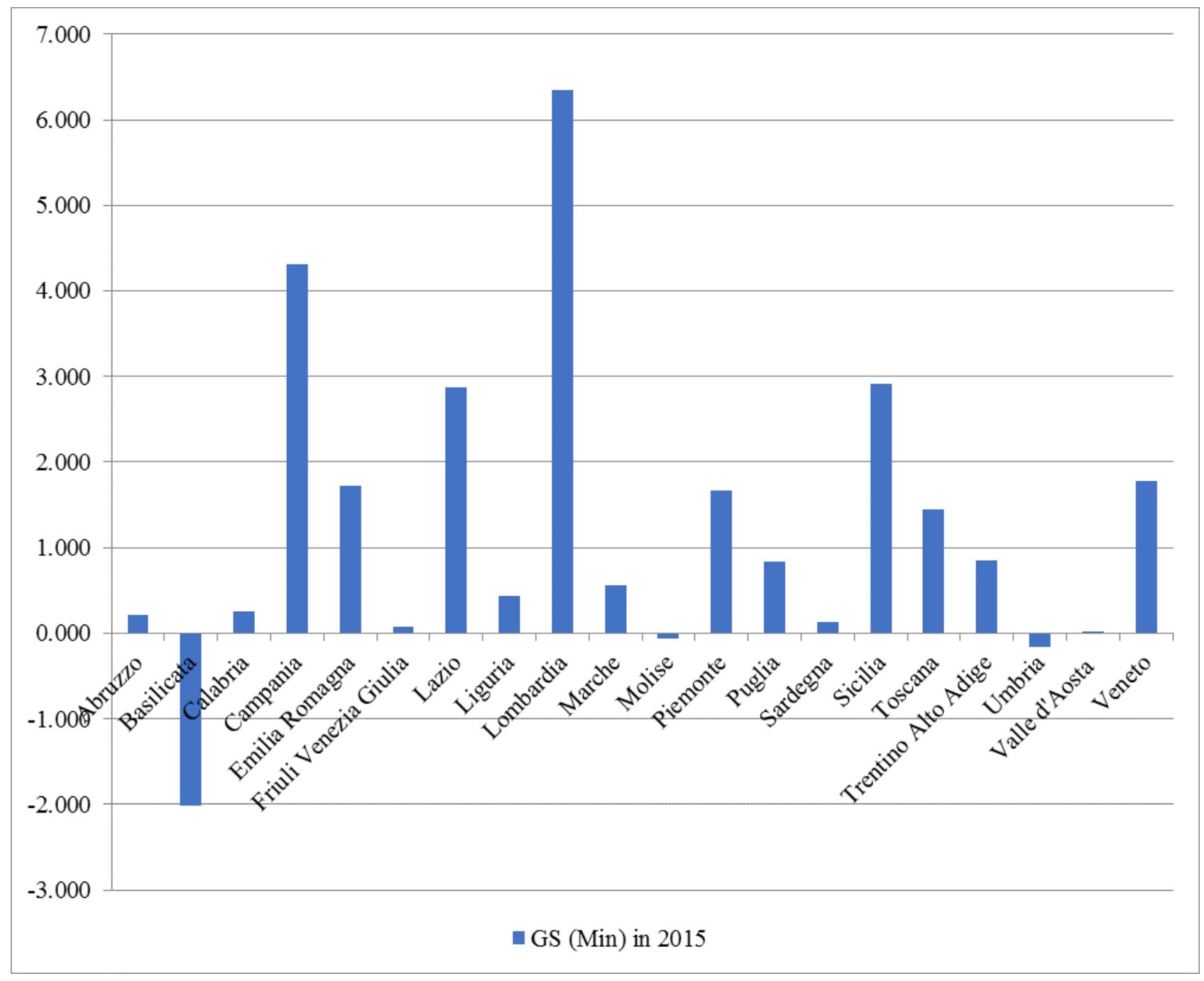

Figure 4 Regional Genuine Saving in $\mathbf{2 0 1 5}$ for Italy (millions of Euro)

For the four years considered (2000, 20052010 and 2015) Table 1 reports the standard estimates of regional Genuine Savings according to minimum and maximum values. All Italian regions, except Basilicata, pass the GS weak sustainability test in 2000 and 2005. Basilicata reports a persistent negative GS since 2005 due to oil and natural gas production. The region hosts the largest onshore field in the South of Europe and presumably the rest of Italian regions benefits from this activity but there is not a formal compensation of this wealth depletion. In the more optimistic scenario, the value of the Basilicata GS in 2015 is equal to $-5.13 \%$ (over regional GDP); in the pessimistic scenario, the index falls dramatically to $-15.86 \%$. This result signals that the region is over consuming its wealth; or, that is not recovering this loss with investments in other forms of capital that could compensate for the current depletion of its natural capital. This implies that the 
development path of the region is not sustainable and this can lead to future lower levels of wellbeing $^{10}$.

In 2010, Emilia Romagna, Liguria and Sardegna presented a GS close to the threshold, in 2015 Molise and Umbria were close to zero which suggests that attention is needed in managing the total capital of critical areas.

Table 1. Genuine Savings in Italian regions (as \% of regional GDP), considering min and max estimates.

\begin{tabular}{|c|c|c|c|c|c|c|c|c|}
\hline & \multicolumn{2}{|c|}{2000} & \multicolumn{2}{|c|}{2005} & \multicolumn{2}{|c|}{2010} & \multicolumn{2}{|c|}{2015} \\
\hline & Min & Max & Min & Max & Min & Max & Min & Max \\
\hline Abruzzo & $7.52 \%$ & $9.78 \%$ & $8.27 \%$ & $9.45 \%$ & $2.26 \%$ & $3.43 \%$ & $1.90 \%$ & $3.91 \%$ \\
\hline Basilicata & $5.47 \%$ & $9.87 \%$ & $-3.63 \%$ & $1.13 \%$ & $-12.78 \%$ & $-6.96 \%$ & $-15.86 \%$ & $-5.13 \%$ \\
\hline Calabria & $7.32 \%$ & $11.48 \%$ & $9.89 \%$ & $11.36 \%$ & $3.01 \%$ & $4.95 \%$ & $1.79 \%$ & $4.74 \%$ \\
\hline Campania & $11.50 \%$ & $13.03 \%$ & $10.86 \%$ & $11.89 \%$ & $4.90 \%$ & $6.15 \%$ & $5.12 \%$ & $6.37 \%$ \\
\hline Emilia Romagna & $5.69 \%$ & $6.74 \%$ & $5.61 \%$ & $6.46 \%$ & $0.61 \%$ & $1.55 \%$ & $1.88 \%$ & $2.49 \%$ \\
\hline Friuli Venezia Giulia & $6.26 \%$ & $7.74 \%$ & $6.00 \%$ & $7.19 \%$ & $1.16 \%$ & $2.26 \%$ & $1.44 \%$ & $2.64 \%$ \\
\hline Lazio & $6.93 \%$ & $7.83 \%$ & $6.21 \%$ & $6.85 \%$ & $1.79 \%$ & $2.55 \%$ & $2.48 \%$ & $3.13 \%$ \\
\hline Liguria & $6.36 \%$ & $7.55 \%$ & $4.93 \%$ & $6.03 \%$ & $0.96 \%$ & $1.89 \%$ & $1.87 \%$ & $2.56 \%$ \\
\hline Lombardia & $6.67 \%$ & $7.40 \%$ & $6.12 \%$ & $6.74 \%$ & $1.14 \%$ & $1.86 \%$ & $2.23 \%$ & $2.74 \%$ \\
\hline Marche & $7.19 \%$ & $8.49 \%$ & $5.99 \%$ & $7.10 \%$ & $1.42 \%$ & $2.56 \%$ & $2.31 \%$ & $3.49 \%$ \\
\hline Molise & $7.85 \%$ & $11.43 \%$ & $7.30 \%$ & $9.89 \%$ & $1.34 \%$ & $3.34 \%$ & $0.37 \%$ & $3.79 \%$ \\
\hline Piemonte & $7.24 \%$ & $8.57 \%$ & $6.72 \%$ & $7.64 \%$ & $1.30 \%$ & $2.41 \%$ & $2.15 \%$ & $3.26 \%$ \\
\hline Puglia & $7.56 \%$ & $10.11 \%$ & $7.51 \%$ & $9.44 \%$ & $2.46 \%$ & $4.60 \%$ & $3.18 \%$ & $4.48 \%$ \\
\hline Sardegna & $7.95 \%$ & $10.77 \%$ & $7.86 \%$ & $9.86 \%$ & $0.52 \%$ & $2.76 \%$ & $1.45 \%$ & $3.21 \%$ \\
\hline Sicilia & $10.10 \%$ & $11.65 \%$ & $8.98 \%$ & $10.27 \%$ & $2.87 \%$ & $4.76 \%$ & $4.48 \%$ & $5.47 \%$ \\
\hline Toscana & $6.88 \%$ & $7.96 \%$ & $6.24 \%$ & $7.23 \%$ & $1.98 \%$ & $2.83 \%$ & $2.53 \%$ & $3.35 \%$ \\
\hline Trentino Alto Adige & $9.37 \%$ & $10.31 \%$ & $9.63 \%$ & $10.38 \%$ & $2.65 \%$ & $3.33 \%$ & $2.70 \%$ & $3.75 \%$ \\
\hline Umbria & $6.84 \%$ & $9.00 \%$ & $5.80 \%$ & $7.41 \%$ & $1.44 \%$ & $2.78 \%$ & $0.85 \%$ & $3.08 \%$ \\
\hline Valle d'Aosta / Vallée d'Aoste & $9.42 \%$ & $10.66 \%$ & $7.47 \%$ & $8.48 \%$ & $1.52 \%$ & $2.36 \%$ & $1.78 \%$ & $2.98 \%$ \\
\hline Veneto & $6.25 \%$ & $7.50 \%$ & $6.24 \%$ & $7.26 \%$ & $1.41 \%$ & $2.35 \%$ & $1.93 \%$ & $2.89 \%$ \\
\hline
\end{tabular}

Tab.1 confirms that Italian regions experienced a considerable reduction in the amount of Genuine Savings in the period 2000-2015. The main reason of this negative evolution is the persistent decline in the level of standard (economic) savings, that was amplified by the economic crisis, leading to negative net savings in the country, compensated by investments in human capital

\footnotetext{
${ }^{10}$ The negative value of GS for Basilicata is mainly driven by the production of oil and natural gas in the area; indeed, Basilicata can be defined as a "resource rich" region with respect to the rest of the country. However, only a portion of these resources is actually consumed in the area, while a part of this natural capital is exploited elsewhere. In principle, this may determine the negative performance of the region, due to the structure of the index. Nonetheless, it is worth noting that Biasi and Rocchi (2016) apply a correction in order to account for this problem. When the natural capital component is rescaled for an "ecological balance of payment" (that is, considering the value of oil and gas produced and consumed in the area), the value of the index is still negative.
} 
formation (especially in Southern regions, where public investments in education are generally higher when compared to other regions). Figure 5 presents the evolution of GS over time.

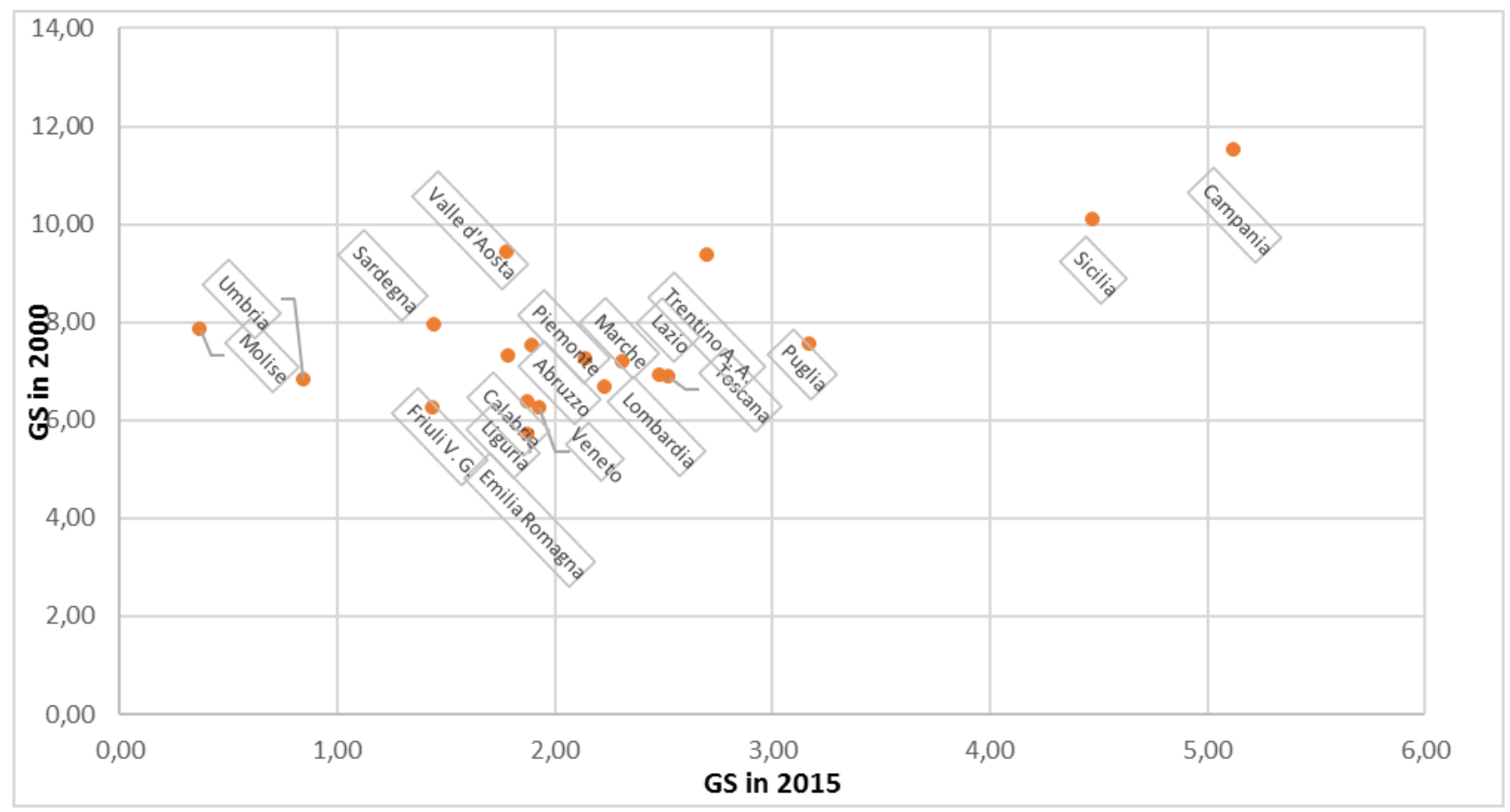

Figure 5 GS as \% of Italian regional GDP in 2000 and 2015.

Regions with similar GS in 2000, as for example Molise and Puglia, present in 2015, a worsening position although the pace of changes differs. The temporal change in GS is another dimension of the indicator which needs to be considered by policy makers. Southern regions (especially Campania, Calabria, Puglia, Sicilia and Sardegna) present higher GS values in 2000 and 2015 suggesting a more sustainable management of the total capital compared to the Northern regions.

Considering now the data available for the damages to single environmental components we can further detail the heterogeneity of Italian regions in terms of sustainability measures. The Northern regions such as Lombardia and Veneto present a higher level of $\mathrm{CO} 2$ emission when compared to the rest of the country. Among Southern ones, Sicilia and Puglia show a remarkable level of emissions; few regions report a (modest) reduction from 2005 onward (Figure 6) 


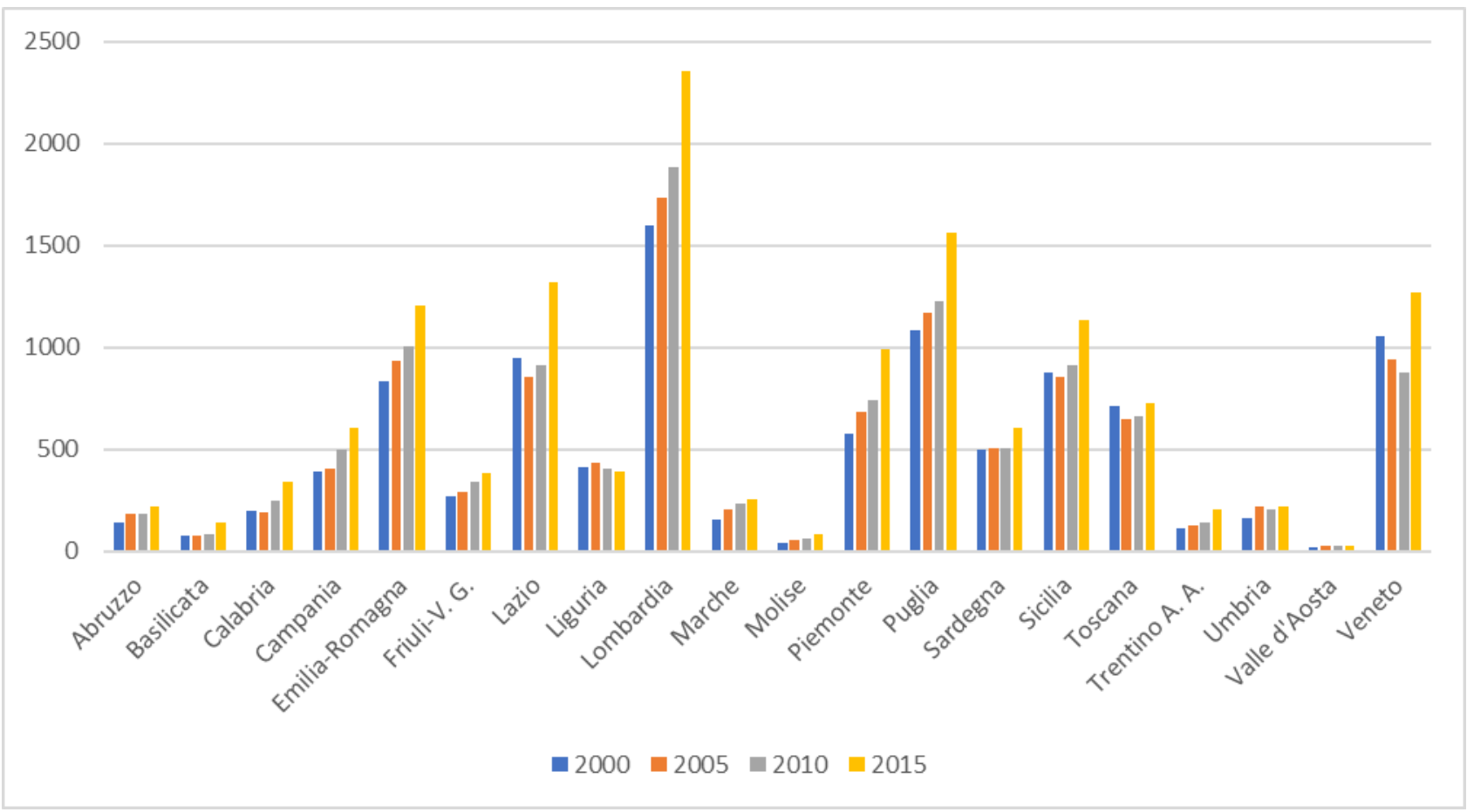

Figure 6. Economic losses due to $\mathrm{CO} 2$ emission in Italian regions (millions of euro)

In terms of air quality degradation due to PM10 emissions, the economic impact of pollution remains a serious issue despite the continuous reduction from 2000 to 2015, especially in regions such as Lombardia, Emilia Romagna, Puglia and Sicilia (Figure 7).

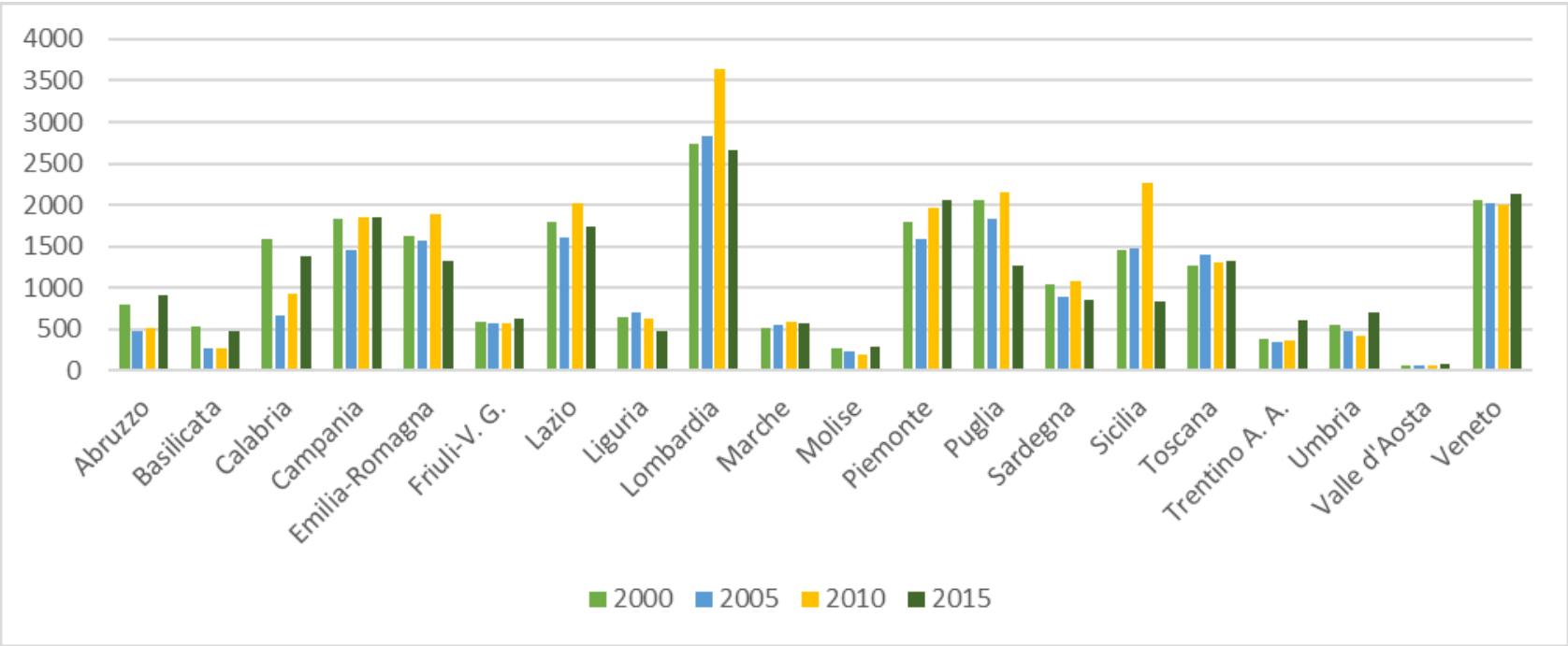

Figure 7. Economic losses due to PM10 emission in Italian regions (millions of euro)

Beside the analysis of air pollution in terms of $\mathrm{CO} 2$ and PM10 emissions, already included in the standard measures of the GS, we can provide also estimates of the damages to two further components of natural capital, i.e. soil and water. Figure 8 reports the loss of $\mathrm{CO} 2$ regulating service due to soil sealing. In 2010 the northern regions of Lombardia and Piemonte show the worst 
performance although in 2015 other regions from the South (Sicilia and Puglia) follow a similar trend. Overall the soil sealing is not particularly pronounced in the period of study in the rest of the country.

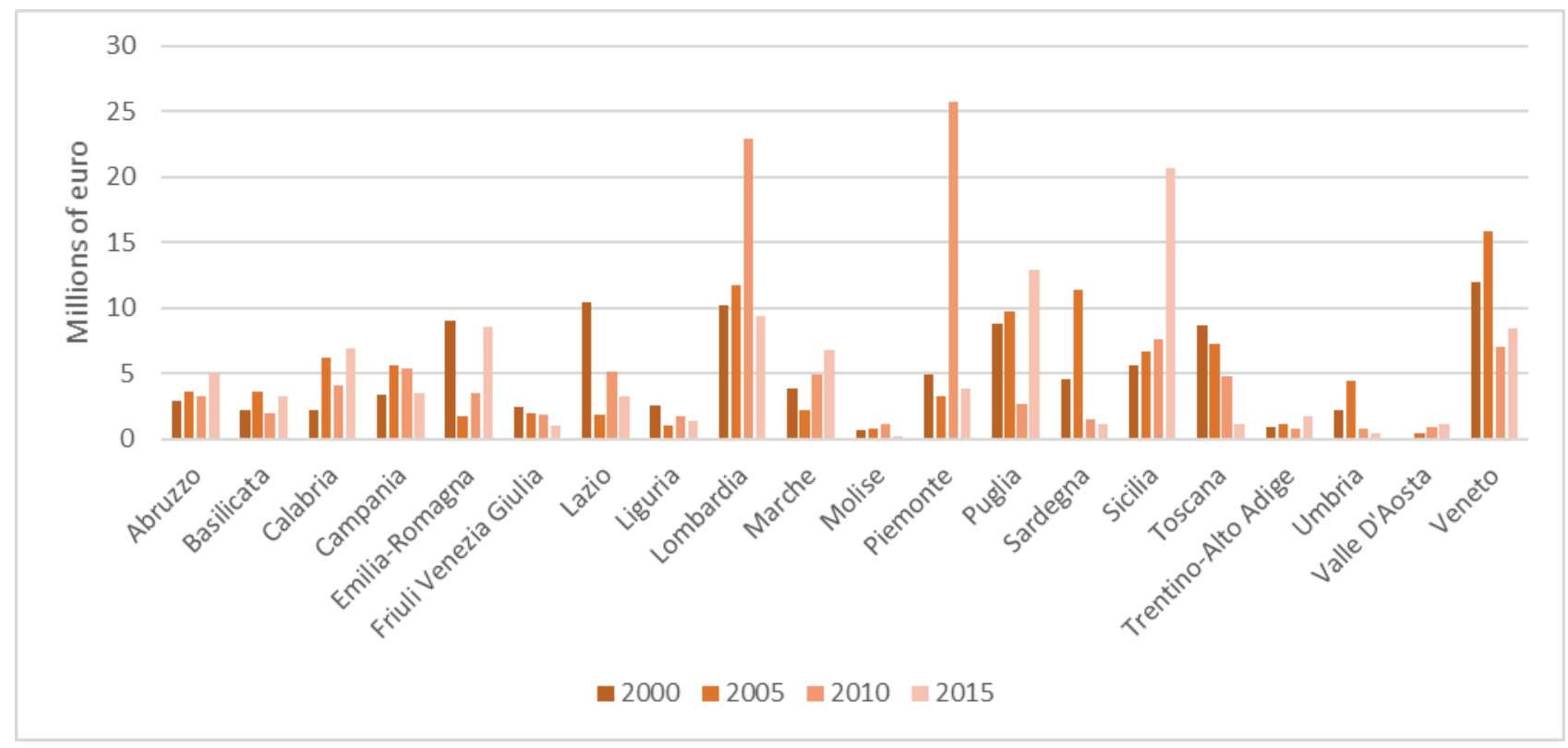

Figure 8. Economic losses due to soil degradation in Italian regions (millions of euro)

In general we can observe that industrial regions like Lombardia, Veneto and Emilia-Romagna present important impacts in term of pollutants (PM10 and water pollution) and soil sealing; contrary, they perform better in term of potable water losses (Fig. 9). The economic impact of water losses is more severe than soil disruption; in total water pollution and losses generates an economic loss of approximately 9000 million of euro in 2015 (that represents $0.56 \%$ of GDP). In this case, Southern regions perform worse. Puglia, Lazio and Sicilia have the most severe level of potable water losses (Fig.9). On the contrary in terms of water pollution Northern regions are still prevailing on the rest of the country (Fig.10). 


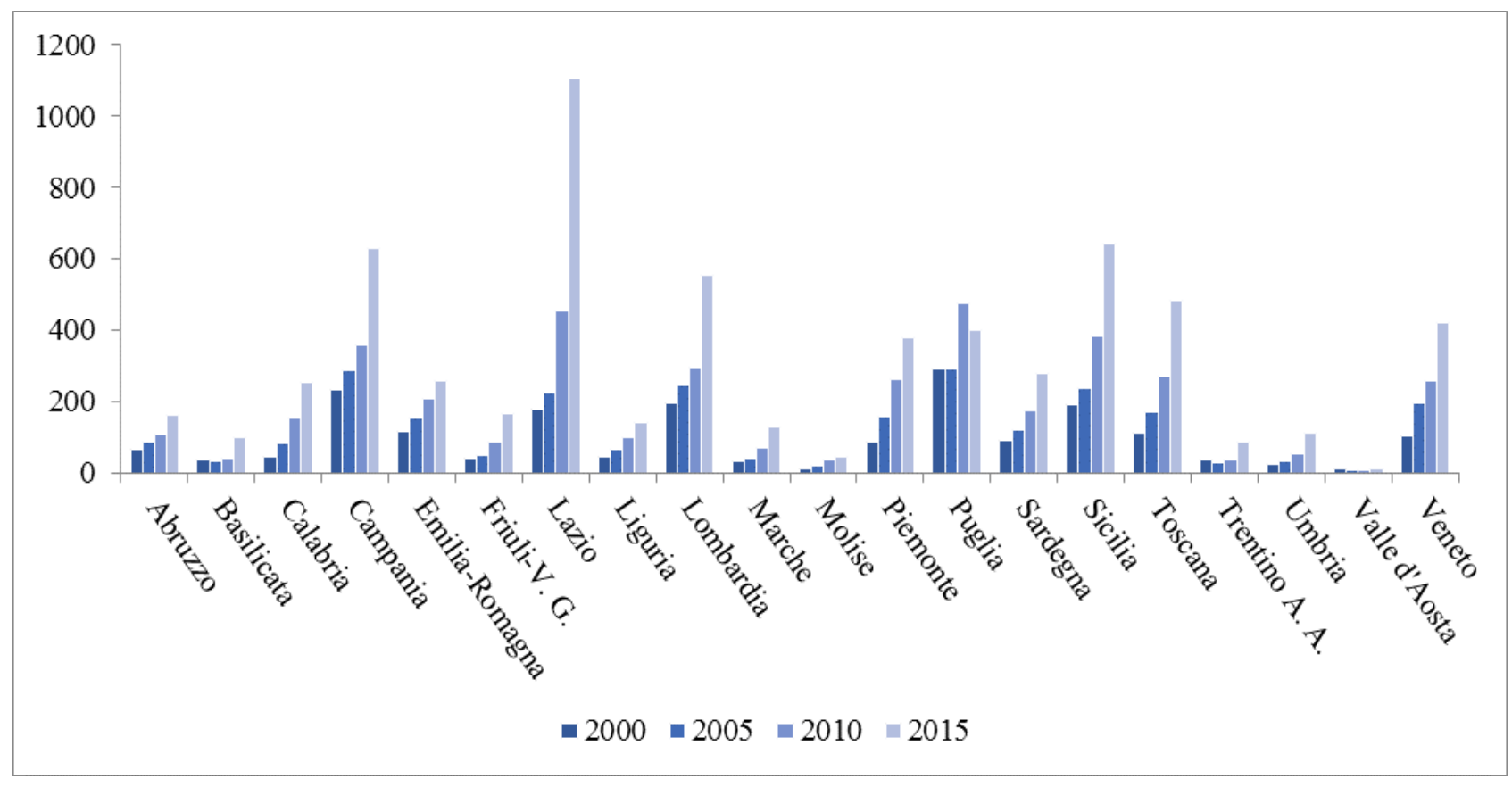

Figure 9. Economic losses due to potable water losses in Italian regions (millions of euro)

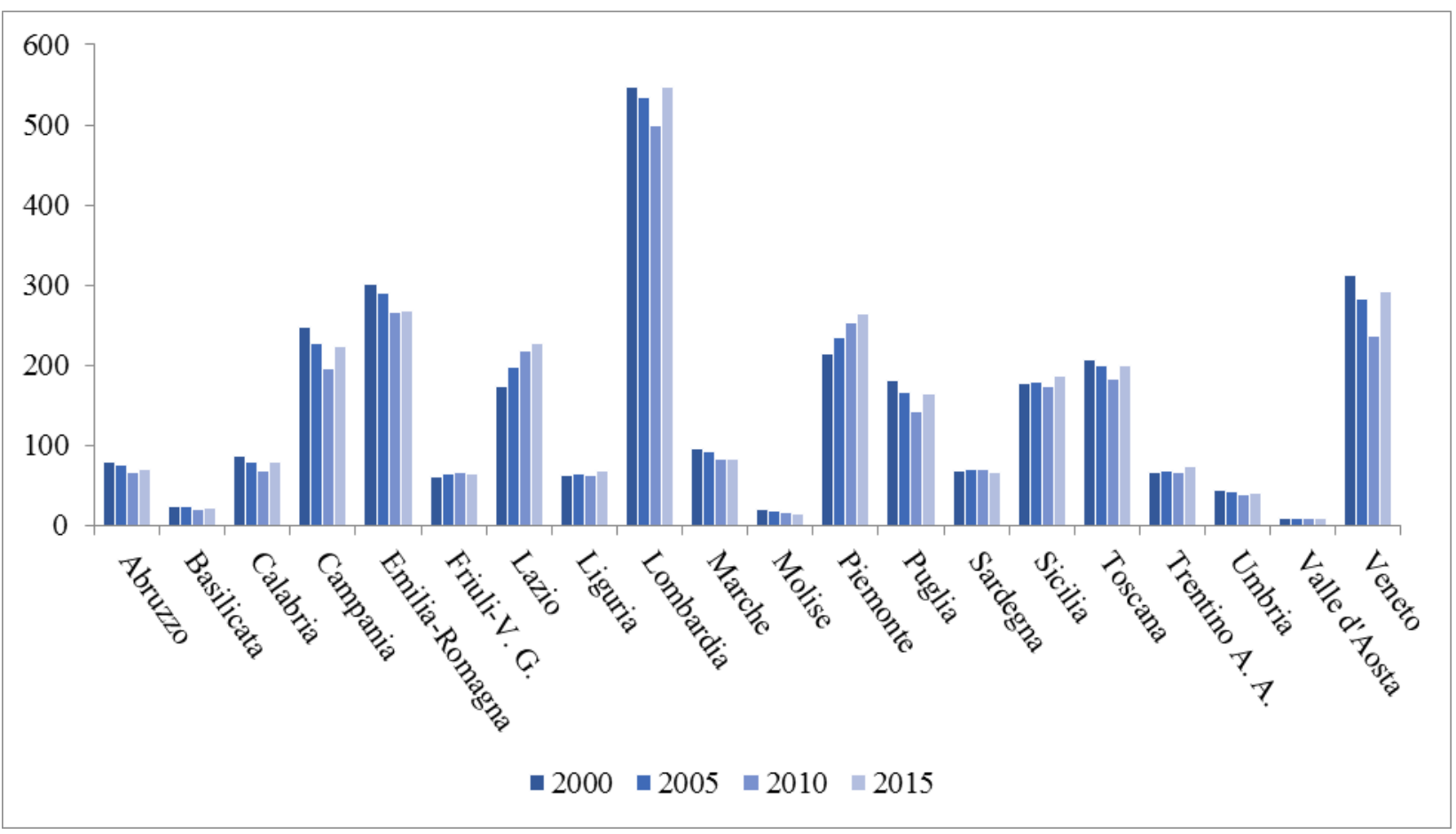

Figure 10. Economic losses due to water pollution in Italian regions (millions of euro)

For 2015 figure 11 summarizes the regional economic losses due to PM, soil and water presenting the values in terms of regional GDP. Not surprisingly, when each figure is expressed in relative terms, the relative importance of economic losses due to air, soil and water components at the regional level is subject to a remarkable change with respect to absolute value. 
b) Soil sealing
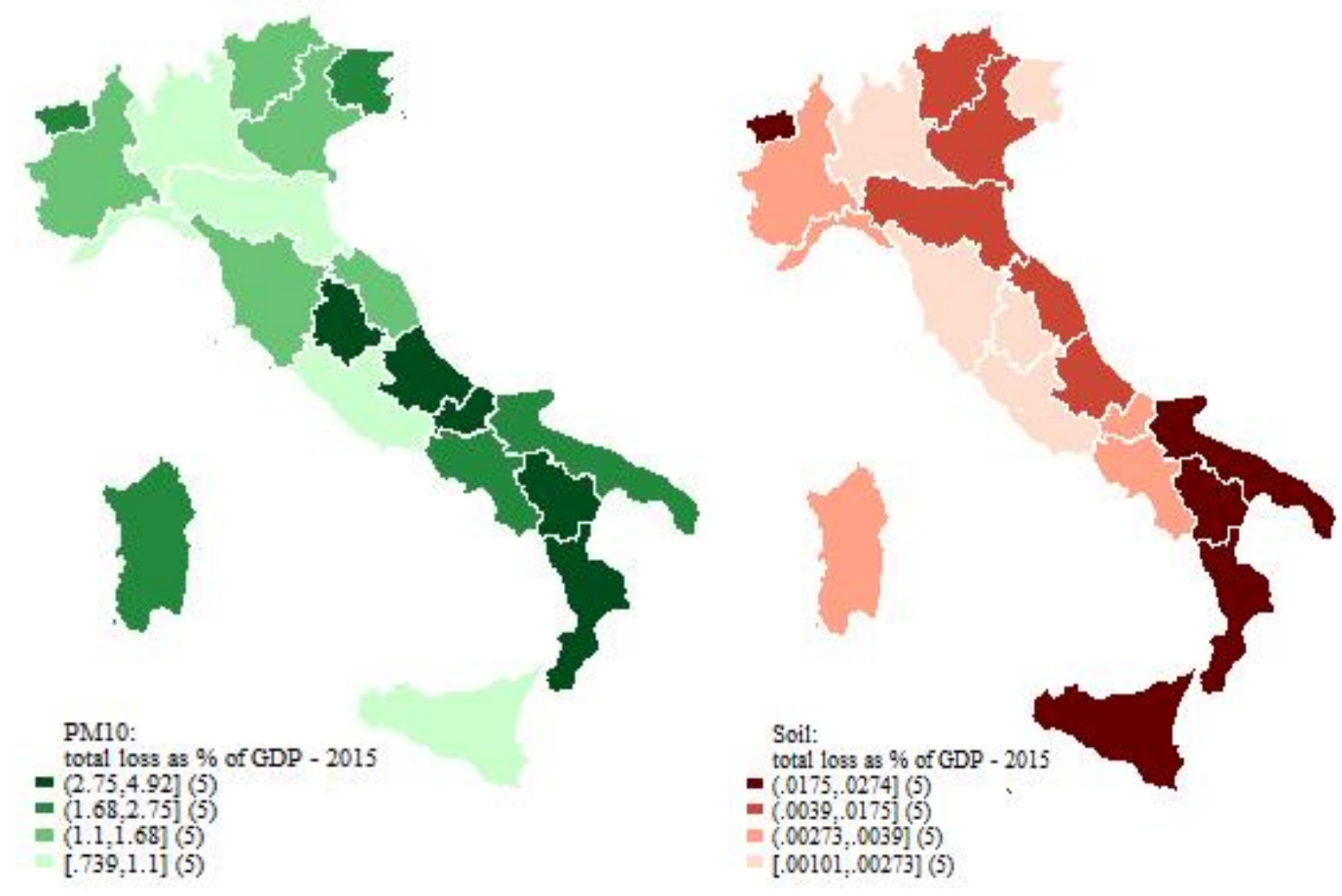

a) Water total losses

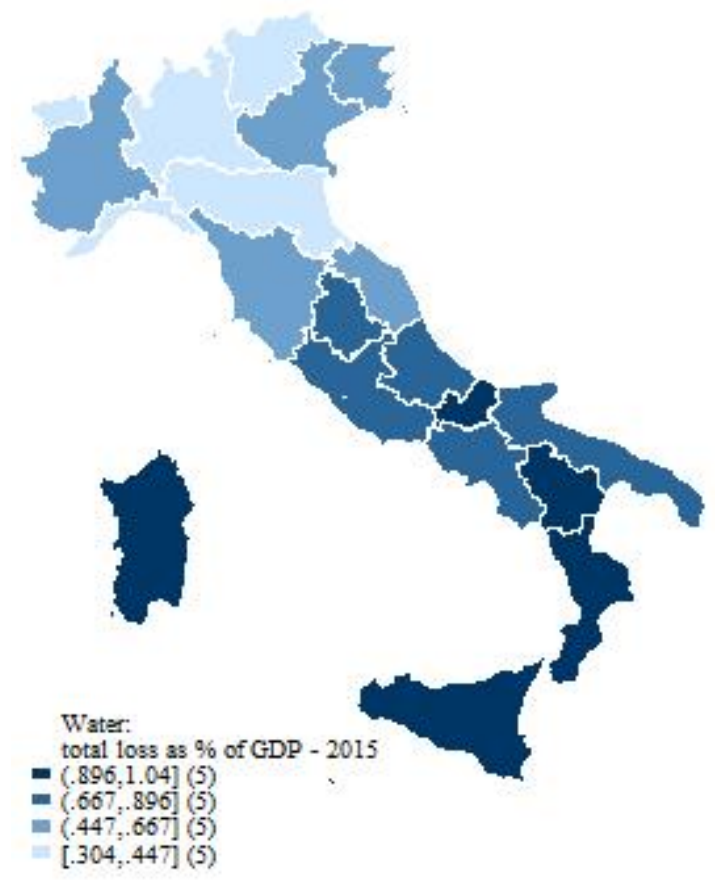

Figure 11. Economic losses due to PM10, soil and water losses in Italian regions (\% of GDP)

Complementing data in Table 1 with water and soil data in Table 2 we derive the extended regional GS. On average regions present an additional impact in absolute terms of roughly $1 \%$ due to water and soil losses, however considering the relative variation the impact is more significant. For example, Molise in 2010 presents a standard GS of 2.29\% (min level in Table1) but after including 
soil and water the GS drops to $1.50 \%$ with a relative impact of roughly $30 \%$. These assets contribute significantly to express the sustainability of growth in the Italian regions. Table 2 shows that more Regions are closer to zero and at risk to fail the test of sustainability than in Table 1.

Table 2. Extended Genuine Savings in Italian regions including water and soil (as \% of regional GDP).

\begin{tabular}{|l|rr|rr|rr|r|r|}
\cline { 2 - 8 } \multicolumn{2}{c|}{} & \multicolumn{2}{c|}{2000} & \multicolumn{2}{c|}{2005} & \multicolumn{2}{c|}{2010} & \multicolumn{2}{c}{2015} \\
\hline & \multicolumn{1}{c|}{ Min } & \multicolumn{1}{c|}{ Max } & \multicolumn{1}{c}{ Min } & Max & Min & Max & Min & Max \\
\hline Abruzzo & $6.90 \%$ & $9.16 \%$ & $7.67 \%$ & $8.85 \%$ & $1.69 \%$ & $2.85 \%$ & $1.15 \%$ & $3.16 \%$ \\
Basilicata & $4.82 \%$ & $9.21 \%$ & $-4.17 \%$ & $0.58 \%$ & $-13.35 \%$ & $-7.53 \%$ & $-16.91 \%$ & $-6.17 \%$ \\
Calabria & $6.81 \%$ & $10.97 \%$ & $9.35 \%$ & $10.82 \%$ & $2.32 \%$ & $4.27 \%$ & $0.73 \%$ & $3.68 \%$ \\
Campania & $10.91 \%$ & $12.44 \%$ & $10.33 \%$ & $11.36 \%$ & $4.35 \%$ & $5.60 \%$ & $4.29 \%$ & $5.53 \%$ \\
Emilia Romagna & $5.30 \%$ & $6.34 \%$ & $5.27 \%$ & $6.11 \%$ & $0.27 \%$ & $1.21 \%$ & $1.52 \%$ & $2.14 \%$ \\
Friuli Venezia Giulia & $5.89 \%$ & $7.36 \%$ & $5.66 \%$ & $6.85 \%$ & $0.71 \%$ & $1.82 \%$ & $0.80 \%$ & $2.00 \%$ \\
Lazio & $6.66 \%$ & $7.57 \%$ & $5.96 \%$ & $6.61 \%$ & $1.42 \%$ & $2.18 \%$ & $1.75 \%$ & $2.40 \%$ \\
Liguria & $6.06 \%$ & $7.25 \%$ & $4.64 \%$ & $5.74 \%$ & $0.61 \%$ & $1.54 \%$ & $1.44 \%$ & $2.13 \%$ \\
Lombardia & $6.37 \%$ & $7.11 \%$ & $5.86 \%$ & $6.49 \%$ & $0.91 \%$ & $1.63 \%$ & $1.92 \%$ & $2.43 \%$ \\
Marche & $6.75 \%$ & $8.05 \%$ & $5.64 \%$ & $6.74 \%$ & $1.03 \%$ & $2.17 \%$ & $1.77 \%$ & $2.95 \%$ \\
Molise & $7.23 \%$ & $10.82 \%$ & $6.69 \%$ & $9.28 \%$ & $0.53 \%$ & $2.52 \%$ & $-0.60 \%$ & $2.82 \%$ \\
Piemonte & $6.93 \%$ & $8.27 \%$ & $6.39 \%$ & $7.31 \%$ & $0.87 \%$ & $1.98 \%$ & $1.64 \%$ & $2.75 \%$ \\
Puglia & $6.72 \%$ & $9.26 \%$ & $6.80 \%$ & $8.73 \%$ & $1.56 \%$ & $3.71 \%$ & $2.36 \%$ & $3.67 \%$ \\
Sardegna & $7.29 \%$ & $10.12 \%$ & $7.21 \%$ & $9.21 \%$ & $-0.23 \%$ & $2.01 \%$ & $0.42 \%$ & $2.18 \%$ \\
Sicilia & $9.56 \%$ & $11.11 \%$ & $8.49 \%$ & $9.78 \%$ & $2.23 \%$ & $4.13 \%$ & $3.49 \%$ & $4.49 \%$ \\
Toscana & $6.48 \%$ & $7.56 \%$ & $5.85 \%$ & $6.85 \%$ & $1.55 \%$ & $2.40 \%$ & $1.91 \%$ & $2.73 \%$ \\
Trentino Alto Adige & $8.99 \%$ & $9.94 \%$ & $9.33 \%$ & $10.08 \%$ & $2.37 \%$ & $3.05 \%$ & $2.30 \%$ & $3.35 \%$ \\
Umbria & $6.45 \%$ & $8.61 \%$ & $5.42 \%$ & $7.03 \%$ & $1.01 \%$ & $2.35 \%$ & $0.14 \%$ & $2.38 \%$ \\
Valle d'Aosta / Vallée d'Aoste & $8.85 \%$ & $10.08 \%$ & $7.06 \%$ & $8.07 \%$ & $1.13 \%$ & $1.96 \%$ & $1.34 \%$ & $2.54 \%$ \\
Veneto & $5.87 \%$ & $7.12 \%$ & $5.88 \%$ & $6.89 \%$ & $1.06 \%$ & $2.01 \%$ & $1.46 \%$ & $2.41 \%$ \\
Italia & $6.90 \%$ & $8.23 \%$ & $6.44 \%$ & $7.44 \%$ & $1.23 \%$ & $2.33 \%$ & $1.78 \%$ & $2.79 \%$
\end{tabular}

Figure 12 maps the 2015 regional extended GS for Italy. Two regions have a negative Genuine Savings and four regions are below $1 \%$. However, it is worth noting that most of territories are very close to the threshold that signals unsustainability, according to the weak sustainability perspective of the indicator. The index provides a synthesis of the interaction between the economic performance and the management of natural resources; in general the economic slowdown is associated with a reduction both in the level of savings and in the pressure on resources, such as water and air pollution; this is the case for Italy, as it emerges in our data. On the contrary, expansive phases may boost the level of savings, with a positive impact on the index, but also environmental degradation is expected to increase. Monitoring these trends may offer useful insight in that respect. 


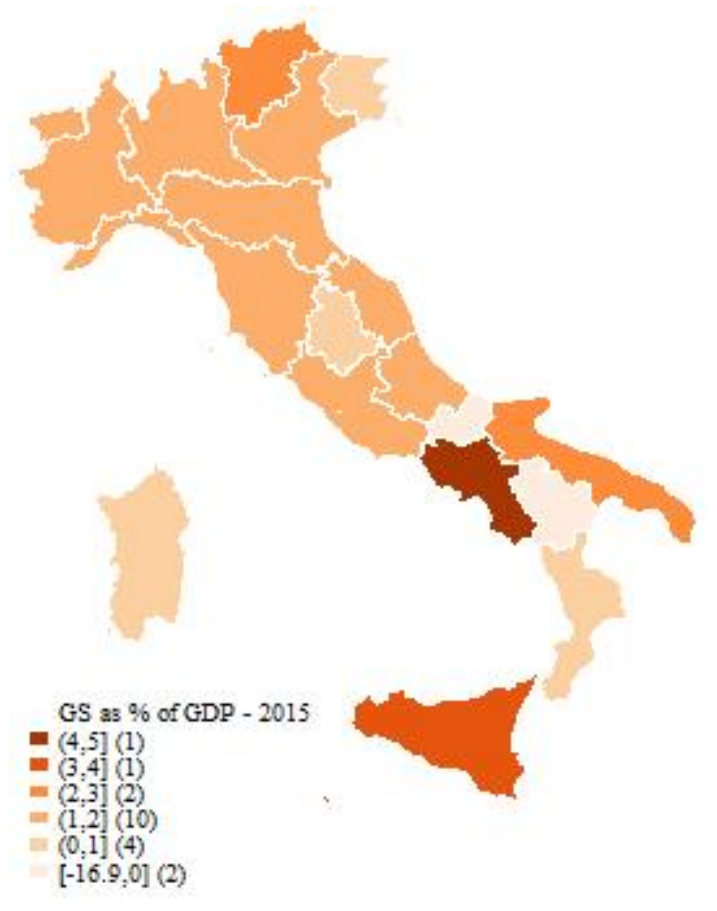

Figure 12. Extended Genuine Saving for Italian regions in 2015 (\% of GDP)

The strength of these two contrasting forces is captured by the index, and will determine the overall impact on long term sustainability.

Table 3 reports the relative variation of GS as from Tab 1 and 2 to appreciate the importance of accounting for the degradation of natural capital and its components.

Table 3. Relative variation of GS in Italian regions due to soil and water components.

\begin{tabular}{|l|rr|rr|rr|rr|}
\hline & \multicolumn{2}{|c|}{2000} & \multicolumn{2}{c|}{2005} & \multicolumn{2}{c|}{2010} & \multicolumn{2}{c|}{2015} \\
\hline & \multicolumn{1}{|c|}{ Min } & Max & Min & Max & \multicolumn{1}{c|}{ Min } & \multicolumn{1}{c|}{ Min } \\
\hline Abruzzo & $-8.2 \%$ & $-6.3 \%$ & $-7.3 \%$ & $-6.4 \%$ & $-25.5 \%$ & $-16.8 \%$ & $-39.5 \%$ & $-19.2 \%$ \\
Basilicata & $-11.9 \%$ & $-6.6 \%$ & $15.0 \%$ & $-48.4 \%$ & $4.5 \%$ & $8.2 \%$ & $6.6 \%$ & $20.4 \%$ \\
Calabria & $-7.1 \%$ & $-4.5 \%$ & $-5.4 \%$ & $-4.7 \%$ & $-22.8 \%$ & $-13.8 \%$ & $-59.3 \%$ & $-22.3 \%$ \\
Emilia Romagna & $-5.1 \%$ & $-4.5 \%$ & $-4.9 \%$ & $-4.5 \%$ & $-11.2 \%$ & $-8.9 \%$ & $-16.3 \%$ & $-13.1 \%$ \\
Friuli Venezia Giulia & $-7.0 \%$ & $-5.9 \%$ & $-6.2 \%$ & $-5.4 \%$ & $-55.9 \%$ & $-22.1 \%$ & $-18.9 \%$ & $-14.2 \%$ \\
Lazio & $-6.0 \%$ & $-4.8 \%$ & $-5.7 \%$ & $-4.8 \%$ & $-38.3 \%$ & $-19.5 \%$ & $-44.1 \%$ & $-24.1 \%$ \\
Liguria & $-4.0 \%$ & $-3.4 \%$ & $-4.0 \%$ & $-3.6 \%$ & $-20.5 \%$ & $-14.5 \%$ & $-29.3 \%$ & $-23.2 \%$ \\
Lombardia & $-4.7 \%$ & $-3.9 \%$ & $-6.0 \%$ & $-4.9 \%$ & $-36.7 \%$ & $-18.7 \%$ & $-23.0 \%$ & $-16.8 \%$ \\
Marche & $-4.4 \%$ & $-3.9 \%$ & $-4.2 \%$ & $-3.8 \%$ & $-20.6 \%$ & $-12.7 \%$ & $-13.8 \%$ & $-11.2 \%$ \\
& $-6.1 \%$ & $-5.2 \%$ & $-5.9 \%$ & $-5.0 \%$ & $-27.8 \%$ & $-15.5 \%$ & $-23.5 \%$ & $-15.5 \%$ \\
Molise & & & & & & & - & $-25.6 \%$ \\
Piemonte & $-7.8 \%$ & $-5.4 \%$ & $-8.3 \%$ & $-6.2 \%$ & $-60.6 \%$ & $-24.3 \%$ & $262.2 \%$ & $-15.5 \%$ \\
Puglia & $-4.2 \%$ & $-3.5 \%$ & $-4.9 \%$ & $-4.3 \%$ & $-33.1 \%$ & $-17.9 \%$ & $-23.6 \%$ & $-18.2 \%$ \\
Sardegna & $-11.1 \%$ & $-8.3 \%$ & $-9.4 \%$ & $-7.5 \%$ & $-36.4 \%$ & $-19.4 \%$ & $-25.7 \%$ & $-3 \%$ \\
& $-8.2 \%$ & $-6.1 \%$ & $-8.3 \%$ & $-6.6 \%$ & $-27.0 \%$ & $-71.3 \%$ & $-32.1 \%$
\end{tabular}




\begin{tabular}{|l|ll|ll|ll|ll|} 
& & & & & & \\
Sicilia & $-5.3 \%$ & $-4.6 \%$ & $-5.5 \%$ & $-4.8 \%$ & $-22.2 \%$ & $-13.3 \%$ & $-21.9 \%$ & $-18.0 \%$ \\
Toscana & $-5.8 \%$ & $-5.0 \%$ & $-6.2 \%$ & $-5.4 \%$ & $-21.8 \%$ & $-15.3 \%$ & $-24.6 \%$ & $-18.5 \%$ \\
Trentino Alto Adige & $-4.0 \%$ & $-3.7 \%$ & $-3.2 \%$ & $-2.9 \%$ & $-10.6 \%$ & $-8.5 \%$ & $-14.7 \%$ & $-10.6 \%$ \\
Umbria & $-5.7 \%$ & $-4.3 \%$ & $-6.6 \%$ & $-5.1 \%$ & $-29.7 \%$ & $-15.4 \%$ & $-83.0 \%$ & $-22.8 \%$ \\
Valle d'Aosta & $-6.1 \%$ & $-5.4 \%$ & $-5.6 \%$ & $-4.9 \%$ & $-26.1 \%$ & $-16.8 \%$ & $-24.8 \%$ & $-14.8 \%$ \\
Veneto & $-6.1 \%$ & $-5.1 \%$ & $-5.8 \%$ & $-5.0 \%$ & $-24.5 \%$ & $-14.7 \%$ & $-24.5 \%$ & $-16.3 \%$ \\
Average & $-6 \%$ & $-5 \%$ & $-5 \%$ & $-\mathbf{7} \%$ & $-\mathbf{3 3 \%}$ & $-\mathbf{- 1 5 \%}$ & $-\mathbf{4 2 \%}$ & $\mathbf{- 1 7 \%}$ \\
\hline
\end{tabular}

For example, Sardegna in 2010 presented a GS (Min) of $0.52 \%$ but once a wider set of natural components is accounted for the GS in 2010 becomes $-0.23 \%$ with a relative decrease of more than $144 \%$. Other regions present a more modest relative impact of the inclusion of additional natural resources on the measurement of GS: for example in Campania in 2015 the (Max) GS without natural resources is equal to $6.37 \%$ while the extended indicator is $5.53 \%$. On average the worsening regional estimates of GS due to the inclusion of soil and water depletion is between 5\% and $42 \%$. 


\section{Conclusion}

The pressure on natural resources and a broader attention on sustainable development goals stress the importance to develop consistent and simply indicators. The Genuine Saving is a sustainability indicator that can signal if a country is over consuming its wealth. As a comprehensive indicator of wealth the Genuine Saving can play a promising role in supporting sustainable development although drawbacks need to be addressed. This paper proposes an extended measure of Genuine Saving that includes soil and water degradation and tests its suitability to be implemented at the subnational level (NUTS2 regions), to capture the heterogeneity of natural capital assets and provide richer information to policy makers.

In the empirical application the paper estimates the amount of Genuine Savings for Italian regions in the period 2000 - 2015, including the economic losses related to soil sealing, water pollution, drinkable water dispersed. Results show a considerable reduction in the amount of Genuine Savings across Italian regions in the period 2000-2010. According to our estimates several regions present alarming performance in the weak sustainability test for 2010 and 2015; nonetheless, only one region (Basilicata) shows a value of the index that is persistently well below the sustainability threshold. On average the negative impact of soil and water depletion is $1 \%$ of the regional GDP but the spatial diversity of impacts is substantial. Central policy makers could use extended GS results to establish across regions compensations to support the depletion of non-renewable assets that benefits the whole nation but at the costs of threatening the sustainability of a single region (as in the case of oil and gas extraction in Basilicata).

Tailoring the analysis at the regional level and accounting for the depletion of these important natural capital assets, the Genuine Saving indicator can better reflect the trends in natural resource management and help in detecting specific threats and priorities that should be considered to secure a sustainable development path. The methodological development of the indicator captures relevant natural capital assets that can complete the picture of wealth captured by the standard World Bank Genuine Saving. For example, soil sealing reduces the productive potential of land, and has also a negative impact on biodiversity. Water quality and quantity are also crucial for productivity and biodiversity maintenance. We acknowledge that other important components of natural capital (e.g. wetland degradation) remain excluded from the proposed Genuine Saving indicator and represent a challenge for the future of sustainability indicators.

The paper aims at improving the measurement of national capital assets using available data for better assess the sustainability of development of sub-national areas. Results show that the extended Genuine Saving might represent a promising macro indicator that can complement non- 
monetary indicators like the OECD Better Life Index or the Italian Equitable and Sustainable Wellbeing indicators. 


\section{References}

Atkinson, G., Dietz, S., and Neumayer, E. (2014). Handbook of sustainable development. $2^{\text {nd }}$ ed. Edward Elgar Publishing.

Biasi P., Rocchi, B. (2016). The Genuine Savings Indicator: estimates at the sub-national level in Italy”, DISEI Working Papers 02_2016, Università degli studi di Firenze.

Bolt, K., Matete, M., and Clemens, M. (2002). Manual for calculating adjusted net savings. Technical report, Environment Department, The World Bank.

British Petroleum (2016). British Petroleum statistical review, retrieved at http://www.bp.com/en/global/corporate/energy-economics/statistical-review-of-world-energy.html

Brown, R. P. C., Asafu-Adjaye, J., Draca, M. and Straton, A. (2005). How Useful Is the Genuine Savings Rate as a Sustainability Indicator for Regions within Countries? Australia and Queensland Compared. Australian Economic Review, 38: 370-388.

Ciommi M., Gigliarano C., Emili A., Taralli S., Chelli F.C. (2017). A new class of composite indicators for measuring well-being at the local level: An application to the Equitable and SustainableWell-being (BES) of the Italian Province, Ecological Indicators 76, 281-296

Clarke M., Lawn P., 2017. Is measuring genuine progress at the sub-national level useful? Ecological Indicators, 8, $573-581$

Dasgupta, P. and Maler, K.. (2001). Wealth as a criterion for sustainable development. Beijer Institute Discussion Paper Series No. 140.

European Environmental Agency (2014). Revealing the costs of air pollution from industrial facilities in Europe. Technical report No 20/2014.

European Union (2015). EU Reference document Good Practices on Leakage Management WFD CIS WG PoM. Main Report.

Fisher et al 2009. Defining and classifying ecosystem services for decision making. Ecological Economics, 68 (3): 643-653

Ferreira, S. and Moro, M. (2011) Constructing genuine savings indicators for Ireland, 1995-2005. Journal of Environmental Management 92(3): 542-553.

Ferreira, S. and Moro, M. (2013) Response to the comments on Ferreira and Moro (2011) 'Constructing genuine savings indicators for Ireland, 1995-2005'. Journal of Environmental Management 127: 337-338.

Fleurbaey, M. (2009). Beyond GDP: The Quest for a Measure of Social Welfare. Journal of Economic Literature, 47:4, 1029-1075. 
Hamilton, K. and Atkinson, G. (2006). Wealth, welfare and sustainability: advances in measuring sustainable development. Edward Elgar Publishing.

Hamilton, K. and Clemens, M. (1999). 'Genuine Savings Rates in Developing Countries', World Bank Economic Review 13(2), 24.

Hanley, N., Dupuy, L. and McLaughlin, E. (2015), Genuine Savings and Sustainability. Journal of Economic Surveys, 29: 779-806.

Hanley, N., Motta, I., Faichney, R., and Wilson, M. (1999). Measuring sustainability: a time series of alternative indicators for Scotland. Ecological Economics, 28(1):55-73.

Hartwick, J. M. (1977) Intergenerational equity and the investing of rents from exhaustible resources. The American Economic Review 67(5): 972-974.

Hartwick, J. M. (1990). Natural resources, national accounting and economic depreciation. Journal of Public Economics, 43(3):291-304.

Hicks, J. (1946). Value and Capital. An Inquiry into Some Fundamental Principles of Economic Theory. Oxford: Clarendon Press.

ISTAT (2006). Il sistema delle indagini sulle acque. Anno 1999. Roma: Istituto nazionale di statistica.

ISTAT (2009). Censimento delle risorse idriche per uso civile. Anno 2008. Roma: Istituto nazionale di statistica.

ISPRA (2016). Consumo di suolo, dinamiche territoriali e servizi ecosistemici. Rapporti 248/2016. Istituto superiore per la protezione e la ricerca ambientale.

ISTAT, 2017. Censimento delle acque per uso civile. Anno 2015. Istituto nazionale di statistica, Roma.

ISTAT (2017). Conti nazionali - Edizione Dicembre 2017. Retrieved from www.dati.istati.it

ISPRA, 2019. Disaggregazione regionale dell'inventario nazionale delle emissioni. Available from: http://www.sinanet.isprambiente.it/it/sia-ispra/inventaria/disaggregazione-dellinventario-nazionale2015/view.

Marchetti,M., Bertani, R., Corona, P., Valentini, R. (2012). Changes of forest coverage and land uses as assessed by the inventory of land uses in Italy. Forest,9 (4), pp.170-184.

Menegaki A.,N., Cardoso Marquesc A., Fuinhasc J., (2017) Redefining the energy-growth nexus with an index for sustainable economic welfare in Europe. Energy, 141, 1254-1268.

Mota, R. P., D. T. and Martins, V. (2010), 'Analysis of genuine savings and potential net national income: Portugal, 1990-2005', Ecological Economics 69. 
Munafo M., Salvati L., Zitti M., (2013). Estimating soil sealing rate at national level—Italy as a case . Ecological Indicators, 26 137-140

Nomisma Energia (2012). Tassazione della produzione di gas e petrolio in Italia: un confronto. Technical Report, Nomisma Energia srl.

Office of Information and Regulatory Affairs, 2013. Technical update of the social cost of carbon for regulatory impact analysis. Retrieved from http://www.whitehouse.gov/ blog/2013/11/01/refining-estimates-social-cost-carbon.

OECD, 2014. In: How's Life in Your Region?: Measuring Regional and Local Well-being for Policy Making. OECD Publishing, Paris. https://doi.org/10.1787/9789264217416-en

Pearce, D. (2002). An intellectual history of environmental economics. Annual review of energy and the environment, 27(1), 57-81.

Pearce, D. W. and Atkinson, G. D. (1993), 'Capital theory and the measurement of sustainable development: an indicator of "weak" sustainability', Ecological Economics 8(2), 103-108. 3, 4, 24.

Polasky, S., Bryant, B., Hawthorne, P., Johnson, J., Keeler, B., Penningtone, D. (2015) Inclusive Wealth as a Metric of Sustainable Development. Annual Review of Environment and Resources, 40: 445-466.

Pulselli, F.M., Ciampalini, F., Tiezzi, E., Zappia, C., 2006. The index of sustainable economic welfare (ISEW) for a local authority: a case study in Italy. Ecological Economics 60 (1), 271-281.

Sallustio, L., Quatrini, V., Geneletti, D., Corona, P., Marchetti, M. (2015). Assessing land take by urban deelopment and its impact on carbon storage. Findings from two case studies in Italy. Environmental Impact Assessment Review 54:80-90.

Schepelmann, P., Goossens, Y., Makipaa, A., Herrndorf, M., Klees, V., Kuhndt, M., \& Sand, I. V. D. (2010). Towards sustainable development: Alternatives to GDP for measuring progress. Report by Wuppertal Institute for Climate, Environment and Energy.

Solow, R. M. (1974), 'Intergenerational equity and exhaustible resources', Review of Economic Studies 41 (Symposium Issue): 29-45.

Solow, R. M. (1986) On the intergenerational allocation of natural resources. The Scandinavian Journal of Economics 88(1): 141-149.

Stiglitz, Joseph E., Amartya Sen, and Jean-Paul Fitoussi (2010) "Report by the commission on the measurement of economic performance and social progress." Paris: Commission on the Measurement of Economic Performance and Social Progress.

UNEP Univ. Int. Hum. Dimens. Program. Glob. Change/UN Environ. Program. 2012. Inclusive Wealth Report 2012: Measuring Progress Toward Sustainability. Cambridge, UK: Cambridge Univ. Press 
UNEP Univ.-Int. Hum. Dimens. Program. Glob. Change/UN Environ. Program. 2014. Inclusive WealthReport 2014: Measuring Progress Toward Sustainability. Cambridge, UK: Cambridge Univ. Press

WCED (1987). Our common future. Oxford University press.

Weitzman, M. L. (1976) On the Welfare Significance of National Product in a Dynamic Economy. Quarterly Journal of Economics 90, 156-162.

World Bank. 2006. Where Is the Wealth of Nations? Washington, DC:World Bank

World Bank. 2011. The Changing Wealth of Nations: Measuring Sustainable Development in the New Millennium. World Bank. 